\title{
ARTIFICIAL INTELLIGENCE AS A HUMAN SUBSTITUTION? CUSTOMER'S PERCEPTION OF THE CONVERSATIONAL USER INTERFACE IN BANKING INDUSTRY BASED ON UTAUT CONCEPT
}

\author{
Batara Daniel Bagana, Moch Irsad, Ignatius Hari Santoso \\ Faculty of Economic and Business, Department of Management, \\ Stikubank University
}

\begin{abstract}
This study aims to analyze the differences in perceptions between customers of Bank Rakyat Indonesia, Bank Negara Indonesia, and Bank Mandiri regarding the use of the conversational user interface of each bank. This study used 58 respondents. The study uses the Kruskal Wallis technique and concluded that there are differences in perceptions between customers of Bank Rakyat Indonesia, Bank Negara Indonesia, and Bank Mandiri who interact using the conversational user interface facility. Even though it is easy to use, the absence of recommendation from the community and family as well as concerns that the chatbot is unable to provide the right information and solution can result in the reluctance of customers to use these facilities in the future.
\end{abstract}

Keywords: artificial intelligence, banking, perception

\section{INTRODUCTION}

It is undeniable that every business organization will always seek an efficient and sustainable business model. This also applies to the Indonesian banking industry. To achieve efficiency, the banking industry has implemented information technology in several work units. For example, the implementation of the human resources information system which will automatically perform administrative work in attendance regarding timekeeping for work and leaving work. Apart from internal use, management information systems are also used to improve service quality to customers.

\footnotetext{
*Corresponding Author.

e-mail: ignatiusharisantoso@edu.unisbank.ac.id
} 
The development of management information systems today is able to change the way business is conducted, how individuals use bank products and services, and even choose bank preferences. Mobile banking technology is one example of the application of management information systems in the banking sector in the early 1990s. In addition, there are other banking information technologies such as contactless payment systems, SMS banking, USSD, automatic teller machines, debit and credit cards, electronic money, telephones banking, and Point of Sales.

All these management information system developments were created to provide a different experience for customers. The leaders of each bank saw that information technology was absolutely essential for the bank to have so that customers remained satisfied and interested in using the bank's products and services. In line with the commitment to provide the best service to customers, bank leaders are slowly but surely starting to shift some fields of work to information and communication technology. In a short time, Teller work is slowly being reduced and replaced by the presence of a cash deposit machine (CDM) that can accept cash deposit transactions, cash withdrawals, and several types of services found in the Teller work unit.

Furthermore, nowadays with artificial intelligence or better known as artificial intelligence, services for customers can be taken over by machines in the form of a conversational user interface or also known as a chatbot. With this conversational user interface, customers seem to be able to interact directly with human customer service, even though the customer is actually interacting with the robot. Artificial intelligence technology is currently growing and becoming smarter so that the responses given when conversing with customers are more personal, just like communicating with an actual person.

The initial stage in the development process of artificial intelligence is machine learning, in which a machine system contains a set of algorithms in its database. The way the machine works is through predefined algorithms. The second stage is machine intelligence, where there are significant developments regarding the algorithm used, which is based on previous experiences. Thus, the machine will give the same reaction if it encounters interaction patterns that have been received from previous customers. It is at this stage that artificial intelligence begins to be applied in the banking industry. 
Even though it has been equipped with experience-based algorithm development, conversational user interfaces as a form of artificial intelligence still do not have a human sense of empathy. Not all messages conveyed by customers can be deeply understood, absorbed, and felt by this conversational user interface. On the other hand, banks as one of the business organizations need to carry out cost efficiency and one way is by substituting humans for machines.

Bank Rakyat Indonesia, Bank Negara Indonesia, and Bank Mandiri are some of the state-owned banks that have chatbot facilities using different messaging application support. Sabrina which is owned by BRI uses the support of Facebook Messenger, Cinta which is managed by BNI applies a more direct chat, while Mita which is developed by Bank Mandiri relies more on the Whatsapp platform to communicate.

The customers of the three state-owned banks are the object of this study because it is the obligation of the BUMN for the welfare of the community. Thus, it is only proper that the three state-owned banks provide the best facilities as well. However, for long-term interests, banking actors need to know the level of customer satisfaction who has used this conversational user interface facility

Based on the background stated above, the researcher formulates the following research questions. Are there different perceptions between customers of Bank Rakyat Indonesia, Bank Negara Indonesia, and Bank Mandiri who interact using the conversational user interface facility?

\section{LITERATURE REVIEW}

\subsection{Artificial Intelligence in the Banking Industry}

Artificial Intelligence is a field of science that specifically studies matters related to information and communication technology capabilities by mimicking the complex human abilities to solve problems. Some of the complex human abilities are reasoning, learning, and self-correction (Alzaidi, 2018). This artificial intelligence system can be applied to a very broad industrial field, one of which is the banking industry. According to Mata et al. (2018), this artificial intelligence system uses complex algorithms that are able to communicate at very high data transfer rates and is designed with the ability to make decisions independently. 
Previously, Mannino et al. (2015) in Alzaidi (2018) reveals that the intelligence system in computers is proven to be more efficient and better when compared to human intelligence and has been proven to be implemented in medical diagnostic systems and the manufacture of driverless cars. With the development of the artificial intelligence system itself, the era of automation has begun and will slowly replace humans. The adoption of artificial intelligence systems in the banking industry has occurred gradually compared to the adoption in other industries. This is due to the high dependence of the banking industry on human resources in carrying out its operational activities.

Some examples of the application of artificial intelligence in the banking sector are the availability of Personalized Financial Services where customers will be assisted by a programmed system to provide investment advice and financial planners automatically based on customer criteria. The system will analyze the character of the customer and provide recommendations on several investment instruments (Vijai, 2019).

The original idea in building computers and even programs was so that they could communicate with humans. This idea was first realized by means of a program developed by Weizenbaum in 1966 called ELIZA which is based on the artificial linguistic internet computer entity (Bastianelli et al., 2016). Not long after that, various smart assistants appeared. Nowadays, these assistants have attracted a lot of public attention through notable examples such as Apple's Siri which is generally considered to be the first voice-based virtual private assistant, Google Assistant developed by Google, Amazon Alexa developed by Amazon, and Samsung. S Voice (One \& Parvez, 2015).

The banking industry sees that artificial intelligence technology as beneficial and is worthy of investment in order to improve service quality to customers because some routine customer questions will be taken over by chatbots as a form of conversational user interface and this will provide new experience for customers in interact with banks (Salunkhe, 2019). Several banks in Indonesia have used a conversational user interface in the form of a chatbot to provide more experience to customers. one of which is Sabrina which was developed by Bank Rakyat Indonesia. In addition, Bank Negara Indonesia gave the name Cinta for their chatbot facility, and Mita for the chatbot facility owned by Bank Mandiri. 


\subsection{UTAUT Concept in the Utilization of a Conversational User Interface}

Unified Theory of Acceptance and Use of Technology is developed by Venkatesh et al. (2003) after studying several previous theories, namely Theory of Reasoned Action, Technological Acceptance Model, Motivational Model, and Theory of Planned Behavior. Some of the constructs of the UTAUT concept used in this study are Performance Expectancy which can be understood as the level of user belief that if he uses a system, it will help and benefit his work (Hartono, 2007).

The next construct is Effort Expectancy which is understood as the level of ease felt by users in using a system. Hartono (2017) explains that Effort Expectancy has previously been found in the Technological Acceptance Model concept which uses the term Perceived Ease of Use, and in the Model of PC Utilization (MPCU) concept which uses the term Complexity. Furthermore, the third construct used in the UTAUT model is Social Influence, which according to Taylor and Todd (1995), is the degree to which an individual believes that the people around him will influence his behavior.

Furthermore, in the UTAUT concept, gender becomes a moderating construct. However, the researcher will not include gender as a moderating construct, but will position gender as a dummy variable as a differentiator in testing the hypothesis. Minton and Schneider (1980) in Hartono (2007) stated that men are basically more task-oriented so that the Performance Expectancy construct tends to be stronger in men than in women. However, Kirchmeyer (2002) stated that gender roles have strong psychological boundaries and change over time.

\subsection{Customer Satisfaction}

Many research topics regarding customer satisfaction have been carried out before, but changes have occurred when customer satisfaction is no longer measured based on the services provided but has shifted towards an experiencebased economy (Kim et al., 2011). Thus, satisfaction will depend on the positive and negative experiences felt by customers (Meyer \& Schwager, 2007). Furthermore, Zeithmal et al. (2011) in Garg et al. (2014) stated that customer experience has a central role in the repurchase process, which in this research can be assumed as the process of using banking products repeatedly. 
The concept of customer experience is the result of various interactions that occur between customers and business organizations which then generate reactions. This customer experience is inherently strong personally and is able to influence customers emotionally, rationally, and in their sensory level (Gentile et al., 2007). In addition, Lenka et al. (2009) revealed that evaluation of customer satisfaction is carried out by comparing customer expectations with experiences gained when customers interact with business organizations such as, in this case, banks.

To predict differences in customer satisfaction in this research, the researchers used several variables tested by Garg et al. (2014), namely Convenience which can be understood as the level of comfort felt by customers while using a combination of the conversational user interface and the Service Process. This could then be understood as a combination of the various interface activities that occur between the customer and the bank as well as the resources the bank needs to produce by providing services to customers.

Currently, the banking industry is starting to use chatbots as a form of conversational user interface to provide new experience for customers. However, as a form of artificial intelligence, chatbots certainly have some limitations that humans do not have, namely a sense of empathy and emotional closeness to customers. Even so, chatbots are certainly more efficient and effective in answering routine and repetitive questions.

The limitations and advantages of each bank's conversational user interface need attention and empirical testing so that banking industry players can predict general customer perceptions. For this reason, the researcher proposes the following hypothesis to be tested in this study.

H1: There are different perceptions between customers of Bank Rakyat Indonesia, Bank Negara Indonesia and Bank Mandiri who interact using the conversational user interface facility?

\section{RESEARCH METHODOLOGY}

In the end, this study only used 58 respondents. Of the total respondents used in this study, 20 respondents were Bank Rakyat Indonesia customers who had used a conversational user interface called Sabrina, 20 respondents were 
Bank Negara Indonesia customers who had used a facility called Cinta, and the remaining 18 respondents were Bank Mandiri customers who had used a chatbot named Mita.

The data collection technique used in this study is printed questionnaires and stationery. In order to determine the appropriate respondents, the researcher made an overview to customers of each bank who have just completed their transactions with customer service staff and being asked to take the time to fill out the questionnaire while maintaining health protocols during the pandemic. Before filling out the questionnaire, the researcher will first confirm that the potential respondent had used the conversational user interface/chatbot facility.

Based on the level of use of the conversational user interface, as many as 47 respondents have only used it once, and the remaining 11 have used it twice. In addition, based on their education level, all respondents are Bachelor graduates.

The measuring instrument in a study is tested through validity testing and testing by comparing the value of $\mathrm{r}$ count with $\mathrm{r}$ table, with the parameter if $\mathrm{r}$ count $>r$ table $(0.218$ for a sample of 56 samples after deducting 2$)$, then the questionnaire item is declared valid. Furthermore, to test the reliability of the measurement model, the researcher used the parameter if Cronbach's Alpha> 0.5 then the measurement item was declared reliable. The measurement scale used in this study is a combination of the UTAUT scale developed by Venkatesh et al. (2003) and Garg et al. (2014). To test the hypothesis proposed, researchers used the statistical package for social science application, especially the Kruskall Wallis method, as one sample non parametric test with a significance level of 5\%.

\subsection{Results}

Tables 1 and 2 below are the results of testing the validity and reliability of the measuring instruments used in this study, respectively.

In accordance with the parameters previously set, based on Table 3 above, we can conclude that there are differences in perceptions between customers of Bank Rakyat Indonesia, Bank Negara Indonesia, and Bank Mandiri who interacted using the conversational user interface facility.

This study proves that in general there are differences in perceptions between Bank Rakyat Indonesia customers who use Sabrina, Bank Negara 
Table 1 Validity Test Result

\begin{tabular}{lcccc}
\hline \multicolumn{5}{c}{ Item-Total Statistics } \\
\hline Scale Mean if \\
Item Deleted & $\begin{array}{c}\text { Scale Variance } \\
\text { if Item Deleted }\end{array}$ & $\begin{array}{c}\text { Corrected Item- } \\
\text { Total } \\
\text { Correlation }\end{array}$ & $\begin{array}{c}\text { Cronbach's } \\
\text { Alpha if Item } \\
\text { Deleted }\end{array}$ \\
\hline ee1 & 35,34 & 47,493 & 0,613 & 0,878 \\
ee2 & 34,84 & 54,379 & 0,286 & 0,888 \\
ee3 & 35,53 & 43,376 & 0,745 & 0,872 \\
att1 & 35,33 & 41,698 & 0,819 & 0,868 \\
att2 & 35,55 & 41,585 & 0,912 & 0,861 \\
att3 & 37,03 & 54,771 & 0,285 & 0,888 \\
sn2 & 37,03 & 54,771 & 0,285 & 0,888 \\
sn3 & 37,05 & 54,752 & 0,298 & 0,887 \\
pbc1 & 35,02 & 55,105 & 0,223 & 0,889 \\
pbc2 & 35,55 & 41,585 & 0,912 & 0,861 \\
pbc3 & 37,03 & 54,771 & 0,285 & 0,888 \\
anx1 & 36,84 & 53,011 & 0,479 & 0,883 \\
anx2 & 34,86 & 52,682 & 0,53 & 0,882 \\
anx3 & 34,86 & 52,682 & 0,53 & 0,882 \\
bi1 & 36,86 & 52,682 & 0,53 & 0,882 \\
bi2 & 36,66 & 52,23 & 0,596 & 0,88 \\
bi3 & 36,72 & 52,624 & 0,527 & 0,882 \\
\hline
\end{tabular}

Source: Data Processed, 2020

Table 2 Reliability Test Result

\begin{tabular}{ccc}
\hline \multicolumn{3}{c}{ Reliability Statistics } \\
\hline $\begin{array}{c}\text { Cronbach's } \\
\text { Alpha }\end{array}$ & $\begin{array}{c}\text { Cronbach's Alpha Based on } \\
\text { Standardized Items }\end{array}$ & N of Items \\
\hline 0,887 & 0,888 & 17 \\
\hline
\end{tabular}

Source: Data Processed, 2020

Table 3 Hypotheses Testing

\begin{tabular}{lc}
\hline \multicolumn{2}{c}{ Test Statistics(a)(,)(b) } \\
\hline \multicolumn{2}{c}{ Tot } \\
\hline Chi-Square & 17,295 \\
Df & 2 \\
Asymp. Sig. & 0 \\
a. Kruskal Wallis Test & \\
b. Grouping Variable: class & \\
\hline
\end{tabular}

Source: Data Processed, 2020 
Indonesia customers who use Cinta, and Bank Mandiri customers who use Mita as a medium of interaction with the bank. However, researchers are interested in looking further at customer perceptions in terms of each construct. For this reason, the researcher made a scale range for each of these constructs with a range of 43.5 points.

In terms of ease of use, customers who use Sabrina developed by Bank Rakyat Indonesia feel that the conversational user interface facility tends to be complicated because it is based on the Facebook Messenger application, while Cinta uses direct chat and Mita uses the Whatsapp application which is much more familiar than Facebook Messenger.

Differences in perception also occur between customers of each bank. For Bank Negara Indonesia and Bank Mandiri customers, the use of the conversational user interface facility is a very interesting idea, while for Bank Rakyat Indonesia customers who have used the Sabrina chatbot this is not an interesting idea. This is assumed because the first experience from using the chatbot does not give a good impression.

In addition, although the conversational user interface facility makes bank services more attractive, the three categories of bank customers simultaneously state that they do not like interaction activities with the chatbot. Furthermore, this study conveyed information that the people around the customers, including families, leaders and offices, generally do not recommend the use of chatbots as a medium of interaction with the bank. Thus, for the Subjective Norms aspect, there are no differences in general views. The absence of recommendations and support from those closest people to them can trigger customer reluctance to use the chatbot facility in the future. This is in line with the concept of group reference in consumer behavior, where consumers often make decisions based on suggestions and recommendations from the community.

In addition, each customer is confident that they have the basic knowledge necessary to interact with the chatbot. The same perception is also held when each customer perceives that the operator is not available when the questions they give to the chatbot are not answered properly. The availability of human operators is very necessary considering the conversational user interface still has shortcomings such as not updating chatbot knowledge on the latest banking products such as the plan to issue Sukuk and Bonds. 
In terms of anxiety, the customers of the three state-owned banks basically do not experience confusion in interacting with the chatbot. However, the three groups of respondents have the same concern on the inability of the chatbot to provide accurate information on the questions submitted by the customer. When the information submitted is not exactly correct, the conversational user interface facility is also said to fail in providing solutions to problems experienced by customers.

Explicitly, this study reveals that the three groups of respondents from Bank Rakyat Indonesia, Bank Negara Indonesia, and Bank Mandiri used in this study have the same perception that they will not use the conversational user interface facility at these banks in the future. For the behavioral intention, there was no difference in perception.

Thus it can be said that although chatbots are easy to use and customers have sufficient knowledge to interact using these facilities, the absence of recommendation from the community and family as well as doubts over the ability of chatbots to provide the right information or solutions have implications for customers' reluctance in keep using it in the future.

\section{CONCLUSION}

Based on the hypothesis testing followed by the discussion in the previous chapter, this study concludes that there are differences in perceptions between customers of Bank Rakyat Indonesia, Bank Negara Indonesia, and Bank Mandiri who interact using the conversational user interface facility.

Some of the limitations contained in this study are the limited number of respondents and its comparison, which is not the same and may cause differences in research results. Apart from that, another limitation is the object of research are only customers from Bank Rakyat Indonesia, Bank Negara Indonesia, and Bank Mandiri. It is also assumed that the gender aspect that is ignored in this study might provide different research results. 
Batara Daniel Bagana, Moch. Irsad, Ignatius Hari Santoso / Artificial Intelligence as a Human Substitution? Customer's Perception of the Conversational User Interface in Banking Industry

\section{REFERENCE}

Alzaidi, A.A. (2018). Impact of Artificial Intelligence on Performance of Banking Industry in Middle East. International Journal of Computer Science and Network Security, Vol. 18, No. 10, pp. 140-148.

Bastianellt, E., Nardi, D., Aiello, L.C., Giacomellt, F., \& Manes, N. (2016). Speaky for Robots: The Development of Vocal Interface For Robotic Application, Applied Intelligence, Vol. 44, No. 1, pp. 43-66.

Garg, R., Rahman, Z., \& Qureshi, M.N. (2014). Measuring Customer Experience in Banks: Scale Development and Validation. Journal of Modelling in Management, Vol. 9, No. 1, pp. 87-117.

Gentile, C., Spiller, N., \& Noci, G. (2007). How to Sustain the Customer Experience an Overview of Experience Component that Co Create Value with The Customer. European Management Journal, Vol. 25, No. 5, pp. 395-410.

Hartono, J. (2017). Sistem Informasi Keperilakuan. Yogyakarta: Penerbit Andi. Kim, S., Cha, J., Knutson, B.J., \& Beck, J.A. (2011). Development and Testing of The Consumer Experience Index, Managing Service Quality, Vol. 21, No. 2, pp. 112-132.

Kirchmeyer, C. (2002). Change and Stability in Manager's Gender Roles. Journal of Applied Psychology, Vol. 87, No. 5, pp. 929-939.

Lenka, U., Suar, D., \& Mohapatra, P.K.J. (2009). Service Quality, Customer Satisfaction, and Customer Loyalty in Indian Commercial Banks. The Journal of Entrepreneurship, Vol. 18, No. 1, pp. 47-64.

Mata, J. (2018). Artificial Intelligence Methods in Optical Network: A Comprehensive Survey. Optical Switching and Network, Vol. 28, pp. 43-57.

Meyer, C., \& Schwager, A. (2007). Understanding Customer Experience. Journal of Consumer Research, Vol. 85, No. 2, pp. 324-332.

Salunkhe, R.T. (2019). Role of Artificial Intelligence in Providing Customer Service with Special Reference to SBI and HDFC Bank. International Journal of Recent Technology and Engineering, Vol. 8, No. 4.

One, M.S. \& Parvez, M.H. (2015). Review of Integrated Application with AIML based Chatbot. International Conference on Computer and Information Engineering, pp. 87-90. 
Taylor, S. \& Todd, P.A. (1995). Understanding Information Technology Usage: a Test of Competing Model. Information System Research, Vol. 6, No. 4, pp. 144-176.

Venkatesh, V., Morris, M.G., Davis, G.B., \& Davis, F.D. (2003). User Acceptance of Information Technology: Toward a Unified Views. MIS Quarterly, Vol. 27, No. 3, pp. 425-478.

Vijai, C. (2019). Artificial Intelligence in Indian Banking Sector: Challenge and Opportunities. International Journal of Advanced Research, Vol. 7, No. 5, pp. 1581-1587. 